\title{
ESTADO E CAPITALISMO NO BRASIL: A INFLEXÃO ATUAL NO PADRÃO DAS POLÍTICAS PÚBLICAS DO CICLO POLÍTICO DA NOVA REPÚBLICA
}

\author{
Marcio Pochmann ${ }^{1}$
}

\begin{abstract}
RESUMO: Dada a posição periférica do país no quadro do desenvolvimento capitalista mundial, a atuação do Estado no capitalismo brasileiro não se submete apenas aos determinantes de natureza interna. Ao partir da abordagem que leva em conta as determinaçóes externa e interna dessa ação estatal no país, buscou-se identificar o movimento atual de inflexão no padrão de políticas públicas constituído pela experiência democrática das últimas três décadas no Brasil. Para tanto, apresentam-se três condicionantes do ciclo político da Nova República, que mostram uma fase de modificação profunda no padrão de políticas públicas desde o impeachment da presidenta Dilma Roussef, em 2016.
\end{abstract}

Palavras-chave: Política. Neoliberalismo. Estado. Capitalismo.

\section{STATE AND CAPITALISM IN BRAZIL: THE CURRENT INFLETION IN THE PATTERN OF PUBLIC POLICIES OF THE POLITICAL CYCLE OF THE NEW REPUBLIC}

\begin{abstract}
Given the peripheral position of the country within the framework of world capitalist development, the State's performance in Brazilian capitalism is not submitted only to determinants of an internal nature. Starting from the approach that takes into account the external and internal determinations of this state action in the country, we sought to identify the current inflection movement in the pattern of public policies constituted by the democratic experience of the last three decades in Brazil. In order to do so, three factors present the political cycle of the New Republic, which show a phase of profound change in the pattern of public policies since the impeachment of President Dilma Roussef in 2016.
\end{abstract}

Keywords: Politics. Neoliberalism. State. Capitalism.

\footnotetext{
${ }^{1}$ Universidade Estadual de Campinas, Instituto de Economia e Centro de Estudos Sindicais e de Economia do Trabalho - Campinas (SP), Brasil. E-mail: mrcpochmann@gmail.com DOI: 10.1590/ES0101-73302017176603
} 


\section{L'ÉtAT et le CAPITALISME AU BRESIL : LA PRESENT INFLECTION DANS LE CADRE DES POLITIQUES PUBLIQUES DU CYCLE POLITIQUE DE LA NOUVELlE REPUBLIQUE}

$R E S U M E$ : Compte tenu de la position périphérique du pays dans le contexte du développement dans le monde capitaliste, le rôle de l'État dans le capitalisme brésilien ne concerne pas seulement les déterminants de nature interne. De l'approche qui tient compte de la détermination interne et externe de l'action de l'Etat dans le pays, nous avons cherché à identifier le mouvement de basculement en cours dans le modèle de la politique publique constituée par l'expérience démocratique des trois dernières décennies au Brésil. À cette fin, nous présentons trois conditions du cycle politique de la nouvelle République qui montrent une période de profond changement dans le modèle des politiques publiques depuis la destitution du président Dilma Roussef, en 2016.

Mots clés : Politique. Néolibéralisme. Etat. Capitalisme.

\section{Introdução}

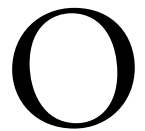

presente ensaio resgata a noção de determinantes do papel do Estado no capitalismo brasileiro com o intuito de identificar o movimento atual de inflexão no padrão de políticas públicas, conformado ao longo do ciclo político da Nova República (1985-2016). Para isso, a reflexão evolui do passado para o presente, buscando evitar dois equívocos metodológicos comuns nas abordagens desconectadas do entendimento do futuro enquanto processo histórico, ou seja:

1. o inconformismo com a situação vigente, produtor de convicçóes súbitas e voluntaristas; ou

2. a acomodação com o estabelecido, geradora de expectativas aprimoradoras do já existente ${ }^{1}$.

Ao mesmo tempo, este texto nega as perspectivas liberal, neoliberal e pós-moderna de análise da realidade. Por ser a-histórica, a concepção liberal narra o perfil do Estado no capitalismo artificialmente e estacionada no tempo, enquanto a abordagem neoliberal concede tratamento mecânico incoerente, simplificado e disfuncional pela visão opositora entre "mais Estado e menos mercado" ou vice-versa. Da mesma forma fragmentadora da realidade, a contribuição pós-moderna abandona a perspectiva de classe e relacional do funcionamento do Estado no capitalismo ${ }^{2}$. 
É sabido que o processo de desenvolvimento capitalista brasileiro constituiu-se assentado direta e indiretamente na atuação do Estado, sobretudo pela natureza das formaçóes sociais ambientadas na tradição autoritária e de transição tardia. Contudo, não será possível aqui analisar ${ }^{3}$ aspectos importantes que constituem o perfil da interveçáo do Estado brasileiro, como, por exemplo, o complexo e extraordinário conjunto de organizaçôes estatais concebido para executar as políticas públicas ao longo do tempo, bem como o montante das despesas, a diversidade do seu sistema de financiamento e o universo da população.

Este texto procura ressaltar as relações estabelecidas pelo Estado no desenvolvimento capitalista brasileiro, cujos modos de intervenção encontram limites nas exigências da acumulaçáo de capital ${ }^{4}$. Se durante o processo de industrialização nacional (1930-1989), por exemplo, o desenvolvimento capitalista transcorreu simultaneamente a própria constituição do Estado moderno, recentemente observa-se que o aparelho estatal passou a sofrer uma reversão considerável de atuação em simultâneo ao processo atual de desindustrialização.

Para além dos compromissos do Estado com o desenvolvimento das forças produtivas e a divisão técnica do trabalho, há também a politização da dominação capitalista que abrange a esfera estatal em resposta aos conflitos sociais com vista à regulação pública do mínimo para manter a existência humana e a participação cidadá. Assim, pela expansão capitalista, o Estado se transforma concomitantemente com o avanço e diferenciação das classes sociais e suas fraçóes em disputa pelo controle do aparelho estatal e de atuaçáo na economia e na sociedade nacional.

Em função disso, a identificação de possíveis determinantes do perfil do Estado no capitalismo brasileiro permite melhor analisar a dinâmica das políticas públicas. Isso é ainda mais notável nas circunstâncias atuais de longa estagnação econômica travestida em instabilidade política, quando o Estado precisa arbitrar riscos, ônus e bônus decorrentes da transformação capitalista sobre as diferentes classes e estratos sociais.

É nessa perspectiva que o ensaio divide-se em duas partes principais. A primeira está voltada ao desenvolvimento teórico da noção de determinantes no perfil do Estado no capitalismo brasileiro, enquanto a segunda aponta o movimento atual de inflexão no padrão de políticas públicas conformado no ciclo político da Nova República.

\section{Determinantes no perfil do Estado no capitalismo brasileiro}

A transição da sociedade agrária-escravista, no último quartel do século XIX, introduziu as bases materiais do Estado capitalista no Brasil. 
Contudo, foi depois dos acontecimentos da década de 1930 que se constituiu um aparato moderno, em simultâneo com as particularidades da revolução burguesa desencadeadora do projeto de industrializaçáo nacional. Sem passado feudal, conforme a experiência europeia, a constituição do Estado capitalista no Brasil perseguiu o caminho liberal tradicional, com a centralização das funções de justiça, coletoria de tributos e defesa territorial.

Mas a trajetória de longo prazo do perfil do Estado no capitalismo brasileiro encontra-se permeada de singularidades quando comparada aos países do centro dinâmico mundial. Como nação periférica e de longeva sociedade agrária, sua industrialização tardia tendeu a limitar-se a pouco mais de meio século de existência. Atualmente, esse capitalismo tardio vive a transição para os serviços e uma nova dependência do comércio externo de produtos primários. Cabe, assim, identificar os determinantes da dinâmica nas políticas públicas no país.

Por conta disso, aborda-se, a seguir, a questão da determinação do perfil do Estado no capitalismo brasileiro. Dois principais determinantes da atuação do Estado são considerados: os de natureza externa e interna à dinâmica de acumulação de capital e suas demais consequências à economia e à sociedade nacional.

\section{Determinantes externos}

Em geral, ao longo do tempo, o Estado tem funcionado em concordância com as exigências da dinâmica capitalista, que se apresenta como um sistema de dimensão global. Esse centro dinâmico torna-se fundamental para combinar - ainda que desigualmente - o heterogêneo conjunto periférico de territórios que o circunda. Para ser um centro dinâmico, há critérios de atendimento de pelo menos três requisitos básicos:

1. moeda como unidade de conta, reserva de valor e meio de troca internacional;

2. poder militar capaz de impor pela força o que a diplomacia não consegue pelo diálogo; e

3. capacidade de produzir e difundir o progresso técnico como motor da competição intercapitalista.

Acontece que, por conta disso, as revoluçóes industriais e tecnológicas se destacam, pois estabelecem não apenas a estrutura da competição intercapitalista como a imposição de novos elementos de mudança no centro dinâmico capitalista. Nesse sentido, o perfil do Estado no capitalismo atenderia aos propósitos de ordem externa ou de dimensão global. 
Em síntese, as determinações na forma de atuação do Estado servem tanto às exigências da estrutura de competição intercapitalista quanto ao formato da dominação exposta pelo centro dinâmico capitalista à periferia global.

Durante o predomínio da livre concorrência capitalista no século XIX, por exemplo, a atuação do Estado era mínima diante da dinâmica de acumulação do capital autorregulada e estabelecedora, por si mesma, da equalização da taxa de lucro. Cabia à organização política do Estado gendarme no liberalismo, fundamentalmente, o exercício do monopólio da violência (controle da ordem policial), da moeda e da tributaçãos.

Com o abandono do capitalismo de livre competição, os limites do Estado mínimo tornaram-se evidentes. A partir do início do século passado, com a expansão da estrutura oligopolista das grandes empresas na produção e distribuição de bens e serviços, a concorrência intercapitalista terminou sendo incorporada à esfera estatal.

As crises recorrentes que levaram à Grande Depressão de 1929 produziram a politização da economia como medida equalizadora da taxa de lucro no interior da competiçâo intercapitalista. Distante da incapacidade de se autorregular, como imaginado pela estrutura da livre competiçáo, a crise tenderia a reproduzir-se continuamente pela destruição do velho capital sem engendrar uma nova fase expansiva associada à tendência concentradora e centralizadora dos novos capitais.

A superação do Estado mínimo pelas exigências da nova estrutura oligopolista de competição intercapitalista moldou outro padrão de intervenção estatal, mais compatível com as exigências da dinâmica de acumulação capitalista. Ao mesmo tempo, mostrou ser favorável à regulação amortecedora dos conflitos sociais inerentes à luta das classes e estratos sociais ${ }^{6}$.

Por conta disso, a possibilidade do estabelecimento inédito de políticas públicas de abrangência nacional para além do Estado gendarme liberal. Ainda na primeira metade do século XX, as políticas nacionais em várias áreas, como economia, trabalho, educação e saúde, entre outras, até então praticamente desconhecidas, passaram a ser difundidas no mundo.

A vigência de uma primeira onda de globalização capitalista, iniciada no século XIX e prolongada até a Primeira Guerra Mundial (1914-1918), tinha a predominância da Ordem liberal hegemonizada pela Inglaterra, que se ancorava no padráo monetário do ouro-libra e na plena liberdade comercial e dos fluxos de capitais e de máo de obra. Com a economia operando sem fronteiras e submetida à dinâmica do imperialismo, ao final do século XIX, as políticas nacionais apresentavam-se frágeis no âmbito do Estado mínimo, quando não submetidas à lógica de dominância das altas finanças da época ${ }^{7}$. 
Pela emergência da Segunda Revolução Industrial e Tecnológica, acompanhada do esgotamento do capitalismo de livre competição, o domínio inglês entrou em decadência, cedendo à Grande Depressão de 1929 e a duas grandes Guerras Mundiais (1914-1918 e 1939-1945), que terminaram por consolidar a nova hegemonia estadunidense mundial após a derrota militar da Alemanha. Com isso, os acordos do final da Segunda Guerra Mundial, como os de Bretton Woods, realizados na área econômica, possibilitaram a generalização das políticas de desenvolvimento nacional, mesmo que acirradas pelo contexto externo da Guerra Fria (1947-1991).

O deslocamento geográfico do núcleo dinâmico mundial da antiga Europa para o continente americano impôs novo reordenamento na relação do centro capitalista com o conjunto da periferia. Com a interrupçáo da primeira onda de globalização estendida no período da Primeira Guerra Mundial (década de 1910) até a Guerra do Irã e Iraque (década de 1970), os antigos impérios deram lugar ao movimento da descolonização, que terminou difundindo grande quantidade de novos países portadores das políticas públicas de caráter nacional.

Foi nesse contexto de ampliação do novo centro dinâmico mundial permeado pela estrutura oligopolista de competição intercapitalista que o papel do Estado modificou-se substancialmente. Assim, as políticas nacionais em diversas áreas ganharam efetividade e eficácia, superando o antigo Estado mínimo por distintas variaçóes de Estado de bem-estar social em sua tarefa de politização da economia e sociedade.

A partir do final da década de 1970, com o esgotamento do ciclo expansivo da Segunda Revolução Industrial e Tecnológica e da estrutura de competição intercapitalista herdada do final do século XIX, a hegemonia dos Estados Unidos passou a registrar contradiçóes importantes. $\mathrm{O}$ abandono dos acordos do Segundo Pós-guerra, que mantinham vigente o padrão monetário ouro-dólar e a estabilidade na taxa de juros e de câmbio, levou à desregulação da competição capitalista e, por consequência, à transformação do Estado e suas políticas públicas nacionais.

Desta forma, uma nova fronteira de expansão capitalista se abriu na Ásia, que, desde a década de 1950, assistia ao deslocamento de parte crescente da produção de manufatura do Ocidente para o Oriente. A desconstituição da Guerra Fria, com a promoção da estratégia militar cibernética pelos Estados Unidos e o esgotamento das experiências de socialismo real, permitiu o realinhamento hegemônico estadunidense amparado na difusão do receituário desregulatório neoliberal nas fronteiras nacionais para o avanço do grande do capital pelas corporaçóes transnacionais.

Isso transcorreu eivado de contradiçôes, como, por exemplo, a nova ameaça à hegemonia estadunidense decorrente do processo de desindustrialização e financeirizaçáo da riqueza em meio à acelerada monopolizaçáo do grande capital portador de cadeias globais de valor e centrada, cada vez mais, na China. 
Uma possível transição no interior do centro dinâmico capitalista mundial pode ser considerada, ainda que não de forma pacífica, seja pelo reaparecimento do protecionismo e do nacionalismo, seja pelo retorno do investimento crescente em armamento militar ${ }^{8}$.

Diante do avanço de uma segunda onda de globalização capitalista, irradiadora de nova e profunda revolução industrial e tecnológica, o padrão de regulação estatal vigente até então foi afetado consideravelmente. É nesse sentido que a estrutura oligopolista de competição capitalista, regulada anteriormente pelos Estados nacionais, terminou dando lugar ao comando de cerca de 500 grandes corporaçóes transnacionais que passaram a monopolizar o sistema gerador de valor operado, fragmentadamente, em não mais do que 300 espaços territoriais do planeta. Essa nova configuração não apenas impacta decididamente a dinâmica do centro global, como altera as relaçóes internas no conjunto da periferia capitalista.

O processo de monopolizaçáo da produção e distribuição da riqueza alcançou a escala global, tendo a grande corporaçáo transnacional cada vez mais poder econômico que os tradicionais Estados nacionais. Por exemplo, somente nove países possuem orçamento público superior ao faturamento dos grandes monopólios privados no mundo. Por força da segunda onda de globalização capitalista, as políticas nacionais de qualquer natureza têm sido questionadas pelo receituário neoliberal desde o último quartel do século passado.

A mudança no papel do Estado acompanha, por decorrência, a pressão de organismos internacionais e dos interesses das grandes corporaçóes transnacionais no interior das decisóes nacionais. Nos dias de hoje, a crise do capitalismo global iniciada em 2008 tem revelado o acirramento da concorrência intercapitalista entre as grandes corporaçóes transnacionais, que vêm operando com taxas de inversão deprimidas, porém articuladas à valorização da órbita financeira.

A dinâmica global da concorrência monopolizada frente à ausência de autorregulação e à insuficiência da regulação pública no âmbito dos Estados nacionais aponta para a nova condição de estagnação secular. Enquanto a órbita financeira dificulta a desvalorização do velho formato do capital, as novas formas capitalistas sofrem barreira no interior da estrutura monopolista de competição dominada pelas grandes corporaçôes transnacionais.

\section{Determinantes internos}

Para além das determinações de ordem externa do capital em relação ao Estado, cabe mencionar também aquelas de natureza interna à organização e ao desenvolvimento estatal no capitalismo brasileiro, a começar pelo fato de 
o país jamais ter reunido os requisitos de centro dinâmico mundial, submetido continuamente à condição de periferia no capitalismo.

Apesar disso, quando não se imaginava solução próxima disponível, o Brasil soube construir convergência política interna capaz de apontar nova direçâo para o desenvolvimento nacional em face à crise de centralidade externa concedida pela Inglaterra até os anos 1910 e pelos Estados Unidos no Segundo Pós-guerra Mundial. Enquanto prevaleceu a primeira onda de globalizaçấo capitalista, cuja centralidade dos impérios dominava as relaçóes internacionais, o Brasil obteve a sua independência nacional, constituiu o Estado mínimo da era liberal e transitou do velho agrarismo escravista para o capitalismo.

Entre 1822 e 1930, por exemplo, a presença das políticas públicas nacionais foi residual, salvo, em geral, no exercício do monopólio da moeda, da violência armada e da arrecadação tributária. Pela construção do Estado gendarme, o país estabeleceu minimamente sua força armada, elevou a soberania com a ampliação das fronteiras territoriais e organizou o sistema produtivo conectado com a primeira onda de globalização como produtor e exportador de produtos primários.

A centralizaçáo administrativa colocada em movimento durante a Monarquia (1822-1889) sofreu importante abalo com o movimento maior da descentralização desencadeada pela política dos governadores instaurada logo após o nascimento da República Velha (1889-1930). Nesse sentido, a transição da antiga e longeva economia escravista para o capitalismo no Brasil transcorreu sob a hegemonia inglesa em meio ao aprofundamento da Segunda Revolução Industrial e Tecnológica, parteira da grande empresa oligopolista.

A ação do Estado pelo liberalismo era reconhecida como estranha e perturbadora à livre competiçáo capitalista. Mesmo assim, em distintas oportunidades, o Estado mínimo terminou ampliando a sua atuaçáo na economia e na sociedade por determinação da dinâmica interna de acumulação capitalista no Brasil.

Para além da expansão nas despesas públicas em relação ao produto, as funçóes estatais foram diversificando-se no domínio do Estado mínimo, sobretudo pelo movimento de decadência inglesa nos estertores da primeira onda de globalização capitalista ${ }^{9}$. A contribuição estatal, em geral, atendeu aos requisitos da dinâmica interna de acumulação assentada no ciclo do café, seja na adoção de política cambial favorável, na validação de empréstimos externos aos cafeicultores ou no subsídio financeiro à importação de mão de obra, entre outros.

Coincidindo com a Grande Depressão de 1929, a crise na economia agrária primário-exportadora encontra soluçáo a partir do projeto 
desenvolvimentista de industrialização e urbanização nacional. Para atender à determinação de ordem interna, o papel do Estado no capitalismo brasileiro modificou-se profundamente, especialmente a partir da Revolução de 1930.

A interrupção da primeira onda de globalização e a realização de acordos internacionais favoráveis ao desenvolvimento capitalista, no final da Segunda Guerra Mundial, mostraram-se positivas à difusão de países e de políticas nacionais em diversas áreas. Contudo, no Brasil, o avanço do projeto de industrialização e urbanização nacional não teve apoio dos Estados Unidos como centro dinâmico mundial.

Durante a Guerra Fria, a Europa contou com o Plano Marshall de ajuda financeira, enquanto alguns países da Ásia (Japão, Coreia do Sul, Taiwan e Hong Kong) também foram beneficiados pelos Estados Unidos, o que não foi constatado na América Latina e Caribe.

Em resposta a isso, o Brasil soube jogar estrategicamente na disputa de hegemonia no interior do centro dinâmico do capitalismo entre os Estados Unidos e a Alemanha para obter vantagens ao avanço de sua industrialização. Também na segunda metade da década de 1950, quando as grandes firmas europeias buscavam responder à internacionalizaçấo das empresas estadunidenses, o país coordenou, com o capital privado nacional e suas empresas estatais, a internalização de um bloco de investimentos estrangeiros capaz de completar a industrialização nacional ${ }^{10}$.

A existência de maioria política interna permitiu recolocar o Estado em novas bases para apoiar a industrialização nacional, ainda que sob o sacrifício do desenvolvimento social. Contribuíram para isso as alianças políticas de caráter conservador e autoritário, que impossibilitaram a realização das reformas clássicas do capitalismo contemporâneo (agrária, tributária e social), geradoras de anomalias como o exacerbado poder dos latifundiários, a iníqua arrecadação do fundo público e a seletividade das políticas públicas para determinados segmentos sociais e setores econômicos privilegiados.

Se de um lado a constituição do Estado brasileiro, após 1930, foi fundamental para a consolidação da nova dinâmica de acumulação com a industrializaçáo, de outro o avanço capitalista deu-se de forma selvagem, ou seja, a modernização capitalista fez-se conservadora, pois responsável por generalizada exclusão no interior da sociedade ${ }^{11}$.

Em mais de meio século de industrialização nacional registrado entre as décadas de 1930 e 1980, o Estado foi conduzido pela maior presença do regime autoritário. Com isso, os interesses dos "de baixo" foram secundarizados frente ao favorecimento das classes rica e média pelo Estado por meio dos monopólios sociais que, seletivamente, privilegiaram segmentos e setores no interior da economia e da sociedade brasileira ${ }^{12}$. 
Quando a industrialização se tornou completa e os limites da ditadura militar (1964-1985) permitiram a retomada da redemocratização no país, a crise da dívida externa se instaurou por consequência das políticas de ajuste neoliberal adotadas pelos Estados Unidos em estímulo à segunda onda de globalização capitalista. Ainda que o Brasil se integrasse somente a partir dos anos 1990 na onda globalizante, os seus impactos sobre a desindustrialização foram significativos, capazes de comprometer o crescimento econômico e submeter a dinâmica da acumulação de capital à lógica da financeirização da riqueza.

Com isso, a transformação do Estado, em pleno regime democrático, mostrou-se ainda mais substancial, tendo que atender tanto à pressão das altas finanças quanto aos compromissos de bem-estar por parte da população ${ }^{13}$. Diante da reestruturação capitalista em curso com a globalização conduzida pelas grandes corporaçóes transnacionais e sob a crescente dominância financeira, a capacidade de o Estado promover políticas públicas de caráter universal apresentou limites políticos e econômicos de ordem interna.

Assim, a experiência democrática constituída pelo ciclo político da Nova República permitiu, por meio da Constituição Federal de 1988, implementar um inédito padrão de políticas públicas convergente com o Estado de bem-estar social observado nos países de capitalismo avançado. Mas isso, por si só, não se mostrou o suficiente para sustentar o regime democrático em face à formação social tradicional com bases conservadoras e autoritárias.

Desde o impeachment da presidenta Dilma Rousseff, em 2016, emergem sinais importantes de inflexão no conjunto de políticas públicas instaurado pelo ciclo político da Nova República. A sucessão de reformas impostas desde entáo, em meio à mais grave recessão econômica dos últimos 100 anos, altera tanto o papel do Estado no capitalismo brasileiro, contemplando o reposicionamento do país junto ao centro dinâmico capitalista mundial, quanto a atuação de uma nova maioria política interna mais favorável aos interesses dominantes. Essa análise é apresentada a seguir.

\section{Inflexão atual no padrão de políticas públicas da Nova República}

A partir do entendimento acerca das determinaçóes externas e internas no perfil do Estado no capitalismo brasileiro, busca-se perscrutar as razóes que apontam para o movimento maior de inflexão atual no padrão de políticas públicas constituído no ciclo político da Nova República. Para tanto, consideram-se as situaçóes tanto externa ao país, que decorre da opção de se alinhar passiva e subordinadamente à segunda onda de globalização capitalista, quan- 
to interna, que emerge da transição precarizada para a sociedade de serviços em pleno avanço da desindustrialização e reprimarização das exportaçóes.

Entre os anos 1985 e 2016, por exemplo, o conjunto dos seis presidentes que sucederam a ditadura militar apresentou como importante elemento de sustentação política do regime democrático o predomínio da coalizão de classes e estratos sociais, que se mostrou incapaz de realizar reformas substanciais na economia e sociedade ${ }^{14}$. Não obstante as importantes diferenças entre si, os governos se pautaram pela legitimidade democrática e pelo cumprimento da Constituição Federal de 1988, que representou um marco inédito na história do país, bem como moldou um padrão de políticas públicas ao longo do ciclo político da Nova República.

A ascensão do governo de Michel Temer, a partir de 2016, tem representado, todavia, a compressão da alargada coalizão de classes sociais por meio de um conjunto de reformas institucionais - derrotadas sistematicamente nas quatro últimas eleiçóes presidenciais - que desconstituem o padrão de políticas públicas conformado desde a transição da ditadura militar. As mudanças na Constituição Federal de 1988 parecem responder direta e indiretamente a determinantes que condicionam o papel do Estado democrático no capitalismo brasileiro desde a instalação da Nova República, em 1985.

Nessa perspectiva, destacam-se a seguir as três condicionalidades principais que caracterizaram o ciclo político da Nova República e que, em pouco tempo, o recente governo Temer aponta por interromper. Dessa forma, o capitalismo brasileiro reposiciona a sua dinâmica de acumulação e impóe, por consequência, uma trajetória de atuação do Estado mais comprometido com a seleta e já privilegiada parcela da populaçáo enriquecida nacional e internacionalmente.

\section{Realinhamento com o velho centro dinâmico global e comprometimento da soberania nacional}

$\mathrm{Na}$ instalação do Mercado Comum do Sul (Mercosul), ainda na segunda metade da década de 1980, quando Brasil e Argentina colocaram fim à polarização instalada de longo tempo, a relação brasileira com os Estados Unidos passou a sofrer importantes modificaçóes. Embora não tenham sido contínuas, inclusive com inflexóes significativas nos governos de Fernando Collor de Mello e Fernando Henrique Cardoso, constatam-se alteraçóes substanciais no período mais recente diante da maior reafirmação da soberania nacional.

A política externa conduzida nos anos 2000 indicou, por exemplo, o reposicionamento do Brasil em base menos passiva e subordinada ao antigo 
centro dinâmico do capitalismo global representado pelos Estados Unidos. Assim, a centralidade nas relaçôes Sul-Sul, a promoção da Uniāo de Naçôes Sul-Americanas (UNASUL) e demais articulaçóes sul-americanas e constitutivas do grupo composto por Brasil, Rússia, Índia, China e África do Sul (BRICS), a política de conteúdo nacional e o apoio à internacionalização da grande empresa brasileira, o novo sistema de defesa fora da esfera estadunidense, entre outros aspectos, mostraram-se decisivos ao enfrentamento da segunda onda de globalização capitalista ${ }^{15}$.

Mas isso não contou, como era de se esperar, com o apoio estadunidense. De certa forma e guardada a proporção devida, o Brasil reconectava-se com experiências de crise no interior do centro dinâmico do capitalismo global, como verificadas nas décadas de 1880 (Inglaterra) e 1930 (Estados Unidos), para trilhar um caminho próprio neste início do século XXI.

Os acontecimentos políticos de 2016 alteraram a correlação de forças internas, bem como descortinaram outro horizonte de submissão externa, convergente com a posição dos Estados Unidos. A inflexão na política externa anterior parece levar ao realinhamento do país com a atual onda de globalização capitalista comprometedora da soberania nacional. Nessa reaproximação com os Estados Unidos, o Mercosul tende a fenecer, bem como as articulaçóes políticas sul-americanas e os BRICS. No seu lugar emerge a defesa mercantilista dos acordos de livre comércio em marcha com a reprimarização da pauta de exportaçóes e secundarização da manufatura.

$\mathrm{Na}$ mesma toada, as políticas tanto de defesa nacional quanto de promoção da internacionalização da economia brasileira, com apoio do Banco Nacional de Desenvolvimento Econômico e Social (BNDES), tendem a ser abandonadas. Acompanha, em certo sentido, o movimento patrocinado pela Operação Lava Jato, que tem produzido enorme prejuízo às corporaçóes nacionais internacionalizadas, assim como na construção civil, nas áreas de petróleo e gás e indústria naval, entre outras.

Além disso, é impulsionada a privatização do que ainda resta do parque produtivo nacional e também a liberalização do comércio de terras aos estrangeiros. As atividades econômicas exitosas, como o agronegócio em terras tropicais, têm sido expostas ao capital monopolista das grandes corporaçôes transnacionais em meio ao noticiário de investigaçóes da Polícia Federal.

No trajeto das cadeias globais de valor, as possibilidades de defesa dos interesses e da soberania nacional, desde a ascensão do atual governo, limitaram-se bastante, salvo aquelas passíveis de incorporação no interior da segunda onda de globalização capitalista. Nesse sentido, tende a ganhar maior impulso o curso de primazia do que há de recursos naturais disponíveis e de 
promoçáo da exportação dos produtos primários, acrescido do esforço interno para tornar o fundo público sustentáculo de longo ciclo dos lucros da financeirização da riqueza.

Tudo isso, é claro, mantida a atual inflexão no padrão de políticas públicas constituídas pelo ciclo da Nova República sem alteração nos próximos anos. A reação política e social, contudo, pode suavizar o seu curso, se não interromper e oferecer, ainda, alternativa distinta.

\section{Reorganização da maioria política para as reformas neoliberais e a asfixia da federação}

A maioria política que se organizou em torno da superação do longo ciclo de superinflação brasileiro (1978-1994) mostrou-se suficiente para garantir a implantaçáo do Plano Real. Porém, os condicionantes levados ao cabo pelo receituário neoliberal inviabilizaram a retomada do crescimento econômico com a inclusão social no Brasil. O pedágio cobrado pelo centro dinâmico global para o ingresso subordinado à segunda onda de globalização capitalista, desde os anos 1980, foi estabelecido pelo Consenso de Washington (1989) na forma de recomendação internacional a ser adotada nas políticas econômicas e sociais nacionais, conforme observado na década de 1990 no país.

O resultado disso foi a maior internacionalização do parque produtivo nacional, com a privatização do setor público e a desindustrialização. $\mathrm{O}$ agravamento econômico e social foi percebido pela populaçáo diante da ausência do crescimento da produção, com o elevado desemprego e a exclusão social, mesmo com a estabilidade monetária alcançada.

Os equívocos na condução da política econômica e social neoliberal tornaram o acesso aos fluxos financeiros dependente da alta taxa real de juros interna, o que levou à valorizaçáo constante da taxa de câmbio, ao estímulo, em consequência, das importaçôes e ao enfraquecimento das exportaçóes dos produtos de maior valor agregado. Nessas condiçóes, as reformas neoliberais perderam fôlego com o esvaziamento da maioria política constituída para a sua sustentação no Brasil.

Diferentemente do ocorrido no país, que aceitou passivamente o programa liberal na década de 1990, outras naçóes utilizaram-se da onda globalizante - o que não significou a uniformização do mundo - para fazer valer soberanamente o conjunto dos seus interesses nacionais. Exemplo disso transcorreu na Ásia, especialmente na China, cuja defesa da política nacional permitiu fazer reformas liberalizantes que possibilitaram avançar a industrialização e modernizar a economia e a sociedade. 
De certa forma, a experiência dos governos nos anos 2000 buscou, mesmo sem negar a existência da segunda onda de globalização capitalista, a condução própria de políticas econômicas e sociais nacionais. A reuniáo de uma base social heterogênea, constituída fundamentalmente por estratos da sociedade perdedores do neoliberalismo da década de 1990, teria sido o suficiente para o estabelecimento de políticas sociais inclusivas e de crescimento econômico sustentável.

Enquanto o país conseguiu aproveitar os ventos favoráveis da globalização, a maioria política negou o retorno do programa neoliberal ${ }^{16}$. Com isso, os governos liderados pelo Partido dos Trabalhadores (PT) consagraram quatro vitórias eleitorais sucessivas, não obstante a oposição neoliberal minoritária e fragmentadamente articulada em torno de alianças políticas internas e externas.

Desde a grande crise iniciada em 2008, a globalização capitalista tem emitido sinais de mudanças importantes em relação à trajetória observada desde a década de 1980. De um lado, e apesar do baixo dinamismo econômico do conjunto dos países, o comércio externo se expandiu a taxas inferiores ao Produto Interno Bruto (PIB) mundial - estimativa de $1,7 \%$ de crescimento do comércio mundial ante $3,1 \%$ de expansão do PIB em 2016 - e a internacionalização das finanças recuou de $20,6 \%$ do PIB mundial em 2007 para $2,6 \%$ em 2015, ao passo que a presença de importados na produção de vários países decaiu - de 71 para 65\% na China e de 44 para 38\% nos Estados Unidos, entre 2007 e 2015$)^{17}$.

De outro lado, o retorno de políticas protecionistas e de expansão dos gastos militares em diversos países, inclusive no centro dinâmico do capitalismo mundial. O enfraquecimento da União Europeia, evidenciada tanto pela vitória do Brexit inglês quanto pela ascensão de forças nacionalistas, soma-se à vitória de Donald Trump nos Estados Unidos com um programa econômico e militar distinto do aplicado até então por Republicanos (Ronald Reagan, George H. W. Bush e George W. Bush) e Democratas (Bill Clinton e Barack Obama).

Nesse contexto, mesmo que talvez tardiamente, o governo Temer conseguiu se tornar, de forma rápida, a expressão de uma maioria capaz de não se opor claramente - por hora - ao retorno do receituário neoliberal. Com o esfacelamento político da barreira desregulatória anterior, as reformas neoliberais passaram a avançar velozmente, retomando ao que não conseguiu realizar nos anos 1990 .

Exemplo disso tem sido também a maior asfixia da federação provocada pela proposição do acerto da dívida de estados e municípios, que projeta a subordinação dos entes subnacionais à lógica da privatização e à destruição 
de instituiçóes capazes de conceder alguma autonomia, bem como os mecanismos de apoio ao desenvolvimento regional e local. Na década de 1990, por exemplo, a adoçáo do programa neoliberal de ajuste dos estados e municípios levou tanto à privatização do patrimônio público da federaçáo em todas as regióes quanto à captura, pelo governo federal, de $\mathrm{R} \$ 277$ bilhóes do orçamento dos entes federados, tendo a dívida pública crescido de $\mathrm{R} \$ 111$ bilhóes para $\mathrm{R} \$ 476$ bilhōes entre 1997 e $2016^{18}$.

\section{Redefinição do fundo público para financeirização da riqueza e distanciamento do projeto de sociedade includente}

O baixo dinamismo econômico prevaleceu durante o ciclo político da Nova República, marcado pelo processo de desindustrialização nacional. De 1985 a 2015, por exemplo, a economia nacional cresceu apenas $2,9 \%$ como média anual, ao passo que no período da industrializaçáo, verificado entre as décadas de 1930 e 1970, o PIB registrou variação média anual de $6,5 \%$.

Diante disso, a participação do Brasil no produto mundial, que era de $4 \%$ em 1985, decresceu para 2,9\% em 2015. Mesmo com o menor dinamismo econômico, a carga tributária bruta do Estado brasileiro subiu de $24,1 \%$ para $32,7 \%$ no mesmo período de tempo, o que representou aumento acumulado de $35,7 \%$ ou de $1,0 \%$ como média anual ${ }^{19}$.

Acontece que a carga tributária terminou crescendo mais para os segmentos de renda intermediários da população, como a classe média assalariada e os trabalhadores urbanos. Enquanto a carga tributária aumentou $69,0 \%$ para as pessoas com rendimento mensal de 1 a 2 salários mínimos e $63,0 \%$ para aquelas de 2 a 5 salários mínimos mensais, os segmentos com renda mensal de 15 a 20 e acima de 30 salários mínimos sofreram elevações de $40,3 \%$ e de $44,0 \%$, respectivamente, entre as décadas de 1970 e $2000^{20}$.

Além da maior carga tributária para os estratos sociais de base e intermediários da populaçáo, a distribuição dos recursos arrecadados pelo Estado, durante o ciclo político da Nova República, atendeu a dois segmentos principais. De um lado, o topo da pirâmide distributiva e receptor de transferências orçamentárias, por meio de ganhos no mercado financeiro, beneficiou-se da elevação das despesas com a administração da dívida pública equivalente a $1,8 \%$ do PIB anual durante o final da ditadura militar para cerca de 8,0\% do PIB anual vigente entre as décadas de 1990 e 2000. Do outro, está a base da pirâmide social, beneficiada pelas políticas de quase universalização do acesso à educação fundamental e à saúde pública, bem como aos demais programas de transferência de renda. Entre 1985 e 2014, 
por exemplo, o gasto social no país saltou de $13,5 \%$ para $22,5 \%$ do PIB, fruto do processo de inclusão social, sobretudo aos segmentos mais vulneráveis da população, como verificado nos anos $2000^{21}$.

Com a divisão no conjunto das despesas públicas durante o ciclo da Nova República, os trabalhadores organizados e a classe média assalariada terminaram sendo menos beneficiados relativamente. Além disso, esses mesmos estratos sociais foram mais penalizados pelo avanço da desindustrialização que destrói relativamente mais os empregos no setor de manufatura de maior qualificação e rendimento ${ }^{22}$.

Diante da crescente dificuldade na elevação da carga tributária em plena vigência de baixo dinamismo econômico, sobretudo na recessão iniciada em 2015, salvo no caso dos ricos, a pressáo sobre a despesa pública aumentou consideravelmente. Em função disso, a opção pela redução da despesa pública não financeira (primária) se fortaleceu, mesmo que direcionada à base da pirâmide social, passando a permitir novo espaço fiscal para a disponibilizaçâo de um montante seguro de recursos governamentais ao atendimento dos gastos financeiros, geralmente para o topo da sociedade.

É nesse contexto que as reformas em curso buscam oferecer condiçôes para que, nos próximos 20 anos, a dinâmica da acumulação de capital seja sustentada, em grande medida, pelas transferências do Estado brasileiro às despesas financeiras. Isso pode se tornar possível, mesmo em ambiente de baixo dinamismo econômico, com o corte do gasto público não financeiro, especialmente no custeio de pessoal e social e, ainda, nos investimentos públicos, e ampliação das receitas com a privatização e concessões no interior do Estado.

Assim, além do distanciamento do projeto de sociedade includente, o governo Temer faz valer, de forma mais acirrada, um Estado com direção governamental de políticas para fundamentalmente não mais do que um terço da sociedade brasileira.

\section{Considerações finais}

Desde o ano 2016, com a ascensão do governo Temer, o Brasil passou a conviver com sinais importantes de esgotamento do ciclo político da Nova República. Com isso, o padrão de políticas públicas constituído nas últimas três décadas de experimentação democrática aponta para uma profunda inflexão impulsionada pelo retorno do receituário neoliberal ao país.

A abordagem desenvolvida nas páginas anteriores concedeu especial atenção aos determinantes principais do papel do Estado no capitalismo brasileiro, com o intuito de oferecer uma interpretação ensaísta a respeito 
do atual movimento de inflexão no conjunto das políticas públicas. As três características essenciais do padrão de políticas públicas constituído na Nova República foram destacadas, servindo de referência à identificação das alterações implementadas pelo governo Temer.

Nesse sentido, pode-se constatar que a emergência de um novo projeto de governo do tipo conservador, classista e autoritário termina por apontar para o esgotamento do ciclo político da Nova República. Além disso, constatou-se também que a inflexão alcançou as relações internacionais, com o realinhamento brasileiro à atual onda de globalização. A inflexão também se dá nas condiçóes internas do país em face ao avanço das reformas das políticas públicas que as tornam convergentes com o atendimento dos interesses da menor parcela da sociedade.

\section{Notas}

1. Sobre isso, ver: Castro, 1972.

2. Para mais detalhes, ver: Polanyi, 2000; Anderson, 1995; Unger, 2001; Eagleton, 1998.

3. Mais detalhes em Silva, 1986.

4. Ver: Mello, 1977; Draibe, 1985; Fernandes, 1975.

5. Mais detalhes em: Abranches, 1979; Miliband, 1979.

6. Sobre isso, ver mais em: Marshall, 1967; Rimlinger, 1971; Gouch, 1979; Titmuss, 1963.

7. A literatura especializada pode ser encontrada em: Hilferding, 1985; Hobson, 1981; Lenin, 1979; Magdoff, 1978; Hobsbawn, 1989; Brown, 1978, Bukharin, 1984; Schumpeter, 1961.

8. Mais detalhes em: Hardt \& Negri, 2000; Chesnay, 1996; Wood, 2003; Hudson, 2003; Altvater, 1995; Boltanski \& Chiapello, 2009; Coates, 2000; Milberg \& Winkler, 2013; Glattfelder, 2013.

9 Sobre isso, ver mais em: Baer et al., 1976; Silva, 1974; Suzigan, 1976; Villela \& Suzigan, 1975.

10. Ver literatura especializada em: Mello, 1982; Cano, 1985; Tavares, 1986; Guimaraes, 1999.

11. Ver mais em: Santos, 1979; Braga \& Goes de Paula, 1986; Villela \& Suzigan, 1975; Martins, 1977; Henriques, 1999; Pochmann, 2016.

12. Mais detalhes em: lanni, 1977; Diniz, 1978; Pereira, 1977; Martins, 1977; Abranches, 1979; Carvalho, 2008; Nunes, 1997.

13. Sobre isso, ver: Castro et al., 2008; Dain, 2001; Draibe, 1998; Faganani, 2005; Ferreira, 2007; Gentil, 2006; Sallum Jr., 2003. 
14. Adota-se o conceito de ciclo político da Nova República, em vez de $6^{a}$ República brasileira, para os governos de seis presidentes: José Sarney, 1985-1990; Fernando Collor de Mello, 19901992; Itamar Franco, 1992-1994; Fernando Henrique Cardoso, 1995-2002; Luís Inácio Lula da Silva, 2003-2010 e Dilma Rousseff, 2011-2016. O governo Temer, desde 2016, por sua natureza de questionável democracia, encontra-se excluído do conceito de ciclo político da Nova República aqui adotado.

15. Mais detalhes em: Garcia, 2010; 2013; Fiori, 2013; Amorin, 2016.

16. Ver mais em: Barbosa \& Souza, 2010; Belluzzo, 2016; Mattoso, 2013.

17. Ver mais em: Alternatives Economiques, 2017.

18. Sobre a descentralização e política federal contida, ver: Lopreato, 2002; Arretche, 2004; Nobre, 2013.

19. A ampliação do fundo público, contudo, não se deu mais acelerada do que a verificada no período da industrialização. Entre 1930 e 1985, por exemplo, a carga tributária bruta passou de $8,4 \%$ para $24,1 \%$ do PIB brasileiro, o que equivaleu à elevação acumulada de $186,9 \%$ ou $1,9 \%$ como média anual.

20. O segmento com até 1 salário mínimo (sm) de rendimento mensal representou 50,2\% dos brasileiros em 2015, sendo de $26,4 \%$ aqueles com rendimento de 1 a 2 sm mensais e de $11,0 \%$ as pessoas com 2 a $5 \mathrm{sm}$ mensais. O estrato da população com mais de $10 \mathrm{sm}$ mensais equivaleu a $1,9 \%$ dos brasileiros, segundo a PNAD do IBGE.

21. Entre 1985 e 2015, por exemplo, concomitante com a elevação da renda per capita de US\$ 5,7 mil para US\$ 15,1 mil e a queda da inflaçâo de $242 \%$ anuais para $7 \%$, e do peso da dívida externa em relação ao PIB de $50 \%$ para $24 \%$, diminuíram também a taxa de pobreza (de $42 \%$ para $15 \%$ da população) e a desigualdade na renda do trabalho medida pelo índice de Gini (de 0,90 para 0,53 ). Enquanto na educação subiram a presença das crianças na escola (de $81,5 \%$ para 98,6\% no segmento de 7 a 14 anos de idade) e a escolaridade média (de 4,4 anos para 7,7 anos na população de 25 anos e mais); e na saúde aumentou a expectativa média de vida (de 64,7 para 75,4 anos) e caiu a mortalidade infantil (de 56,7 para 13,8 por mil nascidos vivos). Mais detalhes em: Dulci, 2010; Pochmann, 2013; Campelo, 2016.

22. A contençáo dos postos de trabalho que levou ao enxugamento da classe média assalariada e dos trabalhadores industriais organizados foi compensada pela elevação considerável do nível de ocupação no setor de serviços. Nos anos 2000, cerca de $90 \%$ das vagas abertas pagavam até 1,5 sm mensal. Assim, a desindustrializaçáo representou a destruição de empregos de $\mathrm{R} \$ 55$ mil anuais concomitantemente com a geração de postos de trabalho de $\mathrm{R} \$ 15$ mil anuais. Ver mais em Pochmann, 2014a; 2014b. 


\section{Referências}

ABRANCHES, S. Estado e desenvolvimento capitalista: uma perspectiva de análise política estrutural. Dados, n. 20, p. 47-69, 1979.

ALTERNATIVES ECONOMIQUES. La fin de la mondialisation? Alternatives Economiques, Paris, n. 304, 2017.

AlTVATER, E. O Preço da Riqueza. Pilhagem Ambiental e a Nova (Des)Ordem Mundial. São Paulo: Editora da Universidade Estadual Paulista, 1995.

AMORIN, C. Por uma política externa altiva e solidária. In: SADER, E. (Org.). O Brasil que queremos. Rio de Janeiro: LPP/UFRJ, 2016.

ANDERSON, P. Balanço do neoliberalismo. In: SADER, E.; GENTILI, P. (Orgs.). Pósneoliberalismo. Rio de Janeiro: Paz e Terra, 1995.

ARRETCHE, M. Federalismo e políticas sociais no Brasil. Sáo Paulo em Perspectiva, v. 18, n. 2, p. 17-26, 2004.

BAER, W.; NEWFARMER, R.; TREBAT, T.J. Consideraçóes sobre o capitalismo estatal no Brasil. Pesquisa e Planejamento Econômico, Rio de Janeiro, v. 6, n. 3, p. 726, dez. 1976.

BARBOSA, N.; SOUZA, J. A inflexão do governo Lula. In: GARCIA, M.; SADER, E. (Orgs.). Brasil: entre o passado e o futuro. São Paulo: Boitempo, 2010.

BELLUZZO, L. Abertura financeira, política industrial e crescimento. In: SADER, E. (Org.). O Brasil que queremos. Rio de Janeiro: LPP/UFRJ, 2016.

BOLTANSKI, L.; CHIAPELLO, E. O novo espírito do capitalismo. Rio de Janeiro: Martins Fontes, 2009.

BOSCHI, E.; CERQUEIRA, D. Burocracia, clientela e relaçôes de poder. Rio de Janeiro: Iuperj, 1978.

BRAGA, J.; GOÉS de PAULA, S. Saúde e previdência. São Paulo: Hucitec, 1981.

BROWN, M. A economia política do imperialismo. Rio de Janeiro: Zahar, 1978.

BUKHARIN, N. A Economia mundial e o imperialismo. São Paulo: N. Cultural, 1984.

CAMPELO, T. A politica de combate à pobreza que queremos. In: SADER, E. (Org.). $O$ Brasil que queremos. Rio de Janeiro: LPP/UFRJ, 2016.

CANO, W. Desequilibrios Regionais e Concentração Industrial no Brasil. São Paulo: Global, 1985.

CARVALHO, J. Cidadania no Brasil. 11. ed. Rio de Janeiro: Civilização Brasileira, 2008.

CASTRO, A. 7 ensaios sobre a economia brasileira. 2. ed. Rio de Janeiro: Forense, 1972. v. 1.

CASTRO, J.; RIBEIRO, J.A.C.; CHAVES, J.V.; DUARTE, B.C.D.; SIMÓES, H.B. Gasto Social Federal e política macroeconômica. Brasília: IPEA, 2008.

CHESNAY, F. A mundialização do capital. São Paulo: Xamã, 1996.

COATES, D. Models of capitalism. Oxford: Polity Press, 2000. 
DAIN, S. O financiamento público na perspectiva da política social. Economia e Sociedade, Campinas, n. 17, p. 113-140, dez. 2001.

DINIZ, E. Empresário, Estado e capitalismo no Brasil. Rio de Janeiro: Paz e Terra, 1978.

DRAIBE, S.M. O Sistema Brasileiro de Proteção Social. Cadernos de Pesquisa, n. 32, 1998. Rumos e Metamorfoses. Rio de Janeiro: Paz e Terra, 1985.

DULCI, L. Participação e mudança social no governo Lula. In: GARCIA, M.; SADER, E. (Orgs.). Brasil: entre o passado e o futuro. São Paulo: Boitempo, 2010.

EAGLETON, T. As ilusóes do pós-modernismo. Rio de Janeiro: Zahar, 1998.

FAGANANI, E. Política social no Brasil. Campinas: IE/UNICAMP, 2005.

FERNANDES, F. A revolução burguesa no Brasil. Rio de Janeiro: Zahar, 1975.

FERREIRA, M. O Estado brasileiro. São Paulo: PUC/SP, 2007.

FIORI, J. O Brasil e seu "entorno estratégico" na primeira década do século XXI. In: SADER, E. (Org.). 10 anos de governos pós-neoliberais no Brasil. São Paulo: Boitempo, 2013.

GARCIA, M. Dez anos de política externa. In: SADER, E. (Org.). 10 anos de governos pós-neoliberais no Brasil. São Paulo: Boitempo, 2013.

O lugar do Brasil no mundo. In: GARCIA, M.; SADER, E. (Orgs.). Brasil: entre o passado e o futuro. Sáo Paulo: Boitempo, 2010.

GENTIL, D. A Política fiscal e a falsa crise da Seguridade Social brasileira. Rio de Janeiro: IE/UFRJ, 2006.

GLATTFELDER, J. Decoding Complexity: Uncovering Patterns in Economic Networks. Switzerland: Springer, 2013.

GOUCH, I. The political economy on the welfare state. London: Macmillan, 1979.

GUIMARÁES, S. 500 anos de Periferia: uma contribuição ao estudo da política internacional. Porto Alegre: Ed. da Universidade, 1999.

HARDT, M.; NEGRI, A. Empire. Cambridge: HUP, 2000.

HENRIQUES, W. O capitalismo selvagem. Campinas: IE/UNICAMP, 1999.

HILFERDING, R. O capital financeiro. São Paulo: N. Cultural, 1985.

HOBSBAWM, E. Da revolução industrial inglesa ao imperialismo. Rio de Janeiro: Forense, 1989.

HOBSON, J. Estúdio del imperialismo. Madri: Alianza Editorial, 1981.

HUDSON, M. Super Imperialism. London: Pluto Press, 2003.

IANNI, O. Estado e planejamento econômico no Brasil. Rio de Janeiro: Civilização Brasileira, 1977.

INSTITUTO BRASILEIRO DE GEOGRAFIA E ESTATÍSTICA - IBGE. Pesquisa nacional por amostra de domicilios: síntese de indicadores 2015. Rio de Janeiro: IBGE, 2016.

LENIN, V. O Imperialismo. São Paulo: Global, 1979. 
LOPREATO, L. O colapso das finanças estaduais e a crise da federação. São Paulo: Unesp/ UNICAMP, 2002.

MAGDOFF, H. A era do imperialismo. São Paulo: Hucitec, 1978.

MARSHALL, T. Politica social. Rio de Janeiro: Zahar, 1967.

MARTINS, C. Capitalismo de estado e modelo politico no Brasil. Rio de Janeiro: Graal, 1977.

MATTOSO, J. Dez anos depois. In: SADER, E. (Org.). 10 anos de governos pós-neoliberais no Brasil. São Paulo: Boitempo, 2013.

MELLO, J. Capitalismo tardio. São Paulo: Brasiliense, 1982.

. O estado brasileiro e os limites da estatização. Revista Ensaios de Opinião, Rio de Janeiro, v. 5, n. 2-3, p. 14-16, 1977.

MILBERG, W.; WINKLER, D. Outsourcing Economics. Cambridge: CUP, 2013.

MILIBAND, R. O Estado na sociedade capitalista. In: CARDOSO, F.; MARTINS, C. (Orgs.). Política e sociedade. São Paulo: Nacional, 1979. p. 62-70.

NOBRE, M. Imobilismo em movimento. São Paulo: Cia. das Letras, 2013.

NUNES, E. A gramática política do Brasil. Rio de Janeiro: Zahar, 1997.

PEREIRA, L. Estado e subdesenvolvimento industrializado. São Paulo: Brasiliense, 1977.

POCHMANN, M. A vez dos intocáveis no Brasil. São Paulo: FPAbramo, $2014 \mathrm{a}$.

. Brasil sem industrialização: a herança renunciada. Ponta Grossa: UEPG, 2016.

. O mito da grande classe média. São Paulo: Boitempo, $2014 \mathrm{~b}$.

Políticas públicas e situação social na primeira década do século XXI. In: SADER,

E. (Org.). 10 anos de governos pós-neoliberais no Brasil. São Paulo: Boitempo, 2013.

POLANYI, K. A grande transformação. Rio de Janeiro: Elsevier, 2000.

RIMLINGER, G. Welfare policy and industrialization in Europe, America and Russia. New York: J.Wiley, 1971.

SALLUM JR., B. Metamorfoses do Estado brasileiro no final do século XX. $R B C$, São Paulo, v. 18, n. 52, p. 35-52, 2003.

SANTOS, W. Cidadania e justiça. Rio de Janeiro: Campus, 1979.

SCHUMPETER, J. Imperialismo e classes sociais. Rio de Janeiro: Zahar, 1961.

SILVA, F. Avaliaçâo do setor público na economia brasileira. 2. ed. Rio de Janeiro: IPEA, 1974.

SILVA, P. Políticas governamentais e perfis de intervenção. RAP, Rio de Janeiro, v. 20, n. 2, p. 3-28, abr./jun. 1986.

SUZIGAN, W. As empresas do governo e o papel do Estado na economia brasileira. In: SUZIGAN, W. Aspectos da participação do estado na economia. Rio de Janeiro: IPEA, 1976.

TAVAREZ, M. Acumulação de Capital e Industrialização no Brasil. Campinas: IE/ UNICAMP, 1986. 
TITMUSS, R. Essays on the Welfare State. Surrey: Unwin Brothers, 1963.

UNGER, R. Política. São Paulo: Boitempo, 2001.

VILLELA, A.; SUZIGAN, W. Politica do governo e crescimento da economia brasileira. 2. ed. Rio de Janeiro: IPEA, 1975.

WOOD, E. Empire of Capital. London: Verso, 2003.

Recebido em 04 de março de 2017.

Aceito em 19 de abril de 2017. 